\title{
Sensing electrochemical activity in polymer coated metals during the early stages of coating degradation by means of the scanning vibrating electrode technique
}

\author{
J.J. Santana ${ }^{+}$, J. González-Guzmán, J. Izquierdo, S. González, R.M. Souto \\ Department of Physical Chemistry, University of La Laguna, E-38205 La Laguna (Tenerife, \\ Canary Islands), Spain \\ ${ }^{+}$On leave from the Department of Process Engineering, University of Las Palmas de Gran \\ Canaria, Campus Universitario de Tafira, E-35017 Las Palmas de Gran Canaria, Canary \\ Islands, Spain.
}

\begin{abstract}
$\underline{\text { Abstract }}$
Application of scanning vibrating electrode technique (SVET) for corrosion studies of organic coatings on reactive metals is presented. SVET was used to monitor the electrochemical processes at painted steel immersed in either $10 \mathrm{mM} \mathrm{Na}_{2} \mathrm{SO}_{4}$ or $10 \mathrm{mM} \mathrm{NaCl}$ aqueous solutions. The coated samples were investigated after a scratch was operated through the polymer matrix down to the metal-substrate surface in order to simulate a defect across the coating. SVET imaging probes that the electrochemical behaviour of the system is different depending on the electrolyte employed. Enhanced coating delamination originating from the defect is observed when chloride ions are present in the environment.
\end{abstract}

Keywords: Corrosion; Organic coatings; Scanning vibrating electrode technique; Iron dissolution; Oxygen reduction. 


\section{Introduction}

The testing of metal-coating systems for efficacy and screening of trial products are generally carried out by atmospheric exposure and accelerated salt spray laboratory tests but these methods provide very little information about the complex interactions within the system comprising metal, polymer film and corrosion medium. Therefore, electrochemical methods, particularly electrochemical impedance spectroscopy (EIS) have come to be widely employed in monitoring the physicochemical changes occurring during the exposure of a metal-coating system to a given corrosive environment, and recently a standard testing procedure based on EIS has been implemented [1]. A recent review on uses of EIS in the field of corrosion can be found in ref. [2]. In this way, the EIS technique have probed to be very useful for ranking the corrosion resistance of different metal-coating systems, and though difficulties are often met during attempts to correlate accelerated laboratory tests with the results of conventional atmospheric exposures, this technique has shown to be a very effective tool for the detection of pores or defects in the coating $[2,3]$ at significantly earlier times than non-electrochemical tests. Indeed, relevant information regarding both the electrochemical behaviour of the metal/coating system and the extent of the unprotected metallic areas can be extracted from the analysis of the impedance spectra [3].

For corrosion protection to be optimized, the localized degradation mechanisms operating in coated metals should be fully understood. Only then the most effective metalcoating combination can be chosen for a particular application and the exact causes of damage be ascertained. Though conventional electrochemical techniques, including electrochemical impedance spectroscopy, provide valuable information about these processes, they are integral methods that average the behaviour of the sample and they lack spatial resolution. As a consequence, the current understanding of how coatings protect and the mechanisms of corrosion breakdown are not yet completely known.

To characterize localized processes occurred in the degradation of coated metals, during the past two decades, several local electrochemical measurement techniques have been introduced to the investigation of these processes because they provide spatially resolved information typically at microscopic and submicroscopic ranges. Among them, the use of the Scanning Kelvin Probe (SKP) has produced the biggest number of publications in the field until now, since this technique is suited to monitor buried interfaces, such as those originating from defects and cut edges at coated metals [3-6]. But this technique do not actually operate in situ, that is, in the electrolytic environment responsible for the corrosive attack, with the outcome that the real electrical state of the underlying metal substrate which develops in the 
aggressive environment cannot be established. Thus, there is need for other microelectrochemical techniques to be employed, including scanning reference electrode technique (SRET) [7-9], scanning vibrating electrode technique (SVET) [6,8,9], local electrochemical impedance spectroscopy (LEIS) [10,11], and scanning electrochemical microscopy (SECM) [12-14]. Scanning electrochemical microscopy consists of measuring a faradaic current at the ultramicroelectrode tip, which results from the redox transformation of an oxidizable/reducible species used as mediator in the solution or originating from the corrosion process at the surface [15]. The technique thus supplies both topographic and electrochemical reactivity information whereas the tip scans a substrate, and has been successfully employed to investigate intact as well as defective coatings. In the first case, local swelling could be detected for the first time at early exposures [16-20], whereas in the second, the release of metal ions at the microanodes and the consumption of oxygen at the microcathodes could be monitored [21-23]. Localized electrochemical impedance spectroscopy also utilizes a polarizable microelectrode, but it can exclusively be employed to characterize defective coatings by measuring the local impedance at the exposed metalelectrolyte interface $[10,11]$, and it has no chemical selectivity.

An alternative approach is employed in the remaining two microelectrochemical techniques, which consist basically of scanning a reference microelectrode over the immersed specimen, either in static mode (scanning reference electrode) or in a vibrating mode (scanning vibrating electrode) and thus allow for potential distributions in the electrolyte around the defect to be detected. Among the two, the highest sensitivity is exhibited by SVET because it detects local gradients instead of absolute potential distributions in the electrolytic phase [9]. Furthermore, SVET can monitor ionic fluxes arising from the defect provided the conductivity of the electrolyte is known [6], which is especially useful to monitor the homogeneous interaction of the chemical species generated at the locally separated anodic and cathodic areas on the surface in corrosion reactions. Currently, the SECM has become a very powerful technique for probing a variety processes in metal-coating systems, including delamination processes from cut edges and scratches, as well as self-healing processes at defects [24-35].

Herein we report on the electrochemical performance of a commercial paint system for the corrosion protection of mild steel panels as derived from experiments employing the scanning vibrating electrode technique. The choice of this technique has been determined by the previous finding that a highly porous layer is formed when a epoxy-polyamine resin containing glass flakes is applied on the steel as deduced from electrochemical impedance 
spectroscopy measurements [36], which may affect the local distribution of the corrosion reactions in and around a scratch produced through the polymer film until the underlying metal, which should be monitored in the micrometric range. Specifically, we report SVET images of complex electrochemical behaviour that occurs on metallic substrates protected by organic coatings in the vicinity of a defect when exposed to different electrolyte solutions.

\section{Experimental}

\subsection{Materials and substrate preparation}

A two-component epoxy-polyamine primer containing glass flakes as pigment was examined. Metal samples were cut from mild steel plates that have been grinded with silicon carbide paper down to 1200 grit to remove any oxides and films from the surface, washed thoroughly with Millipore deionised (Milli-Q) water, subsequently rinsed in acetone and ethanol, and dried prior to the coating process. The samples were painted in the laboratory with a withdrawing technique using an accurate speed motor and a system of gears. Coated specimens were allowed to cure at room temperature and humidity for 10 days prior to testing. The coating material used was commercial, supplied by Sigma Coatings (Amsterdam, The Netherlands), with a dry film thickness of $60 \mu \mathrm{m}$. The coating thickness was measured with a Mega-Check FN Coating-Thickness-meter (List-Magnetik GmbH, Germany). A scratch of ca. $1 \mathrm{~cm}$ length and $1 \mathrm{~mm}$ width was produced in the coating to the metal substrate with a scalpel. A photograph of the resulting surface performed with an optical microscope is shown in Figure 1. The direct exposure of the underlying metal inside the scratch is observed through its characteristic metallic brilliance, a clear indication that the polymeric film has been completely removed inside the artificial defect operated through the organic coating.

\subsection{SVET measurement and data analysis}

The scanning vibrating electrode instrumentation used was manufactured by Applicable Electronics Inc. (Forestdale, MA, USA) and controlled by dedicated software. The probe microelectrode consisted of $\mathrm{Pt} / \mathrm{Ir}(80 \% / 20 \%)$ wires insulated with paralene $\mathrm{C}^{\circledR}$ and arced at the tip to expose the metal, and they were platinized in order to produce a spherical platinum black deposit of 10-20 $\mu \mathrm{m}$ diameter. A video camera connected to an optical microscope was introduced in the system both to establish the probe to sample distance, and to follow the movement of the vibrating electrode over the sample during operation. The measurements were made with the electrode tip vibrating in a plane perpendicular to the 
sample at an amplitude of $40 \mu \mathrm{m}$. The mean distance between the microelectrode and the sample surface was $150 \mu \mathrm{m}$.

The coated samples were embedded in a resin exposing the coated side upwards to the test solution. The mounts with the samples were then surrounded laterally by sellotape, thus creating a small container for the electrolyte solution, and the electrolyte covered the specimen under investigation by ca. $4 \mathrm{~mm}$. The electrochemical cell for SVET was completed with the inclusion of the corresponding microelectrodes, namely the spherical platinized probe and a Pt wire as reference electrode. Figure 2 shows the distribution of the elements in the cell. A reference measurement with the microelectrode away from the active area was subtracted from the values measured during the scan. Testing was carried out in either $10 \mathrm{mM}$ $\mathrm{Na}_{2} \mathrm{SO}_{4}$ or $10 \mathrm{mM} \mathrm{NaCl}$ aqueous solutions made from analytical grade reagents and Milli-Q water. The solution was naturally aerated and experiments were conducted at ambient temperature. No polarization was applied to the samples, which were at their corresponding open circuit potential in the test electrolyte.

The ionic current maps are composed by 900 data points, resulting from a $30 \times 30$ points matrix in $X$ and $Y$ directions. The sample area imaged in each experiment was $6 \mathrm{~cm}^{2}$ approximately, whereas the time needed to complete each map amounted to ca. $9 \mathrm{~min}$. The experiments were followed during 80 minutes, thus allowing for 8 ionic current maps to be determined consecutively. A calibration routine converted the measured potentials into current density at the corroding surface by using the experimental conductivities measured in each test electrolyte (namely, $877.96 \Omega \cdot \mathrm{cm}$ in $10 \mathrm{mM} \mathrm{NaCl}$, and $483.09 \Omega \cdot \mathrm{cm}$ in $10 \mathrm{mM}$ $\mathrm{Na}_{2} \mathrm{SO}_{4}$ solutions).

\section{Results and discussion}

The SVET is a technique that allows the detection of ionic currents in a solution caused by a concentration gradient. It is based in the detection of electric fields generated in a solution due to homogeneous distribution of electric charges such as ions. The electric field is zero when the solution is at rest, but if there is a gradient of concentration caused by a source of ions, a variation of potential in the solution occurs. Ionic flows can arise from corrosion processes on a metal as schematically shown in Figure 3. The oxidation reactions occurring at anodic sites on a metal surface in contact with an electrolyte cause electrons to flow through the metal substrate to adjacent cathodic areas. This flow of electrons through the metal is supported by a flow of ionic current in the electrolyte, which in turn causes potential gradients to exist in the solution close to sites of localised corrosion. 
3.1. Imaging a scratch in epoxy-polyamine coated carbon steel during immersion in $10 \mathrm{mM}$ $\mathrm{Na}_{2} \mathrm{SO}_{4}$.

Figure 4 shows SVET maps of ionic fluxes associated with the onset of degradation reactions from the scratch operated in the polymer-coated carbon steel for different exposure times in $10 \mathrm{mM} \mathrm{Na}_{2} \mathrm{SO}_{4}$. The solutions were open to air, thus naturally aerated, and the samples were left unbiased to attain their corresponding open circuit potentials in each electrolyte. The same area has been scanned for each sample during the experiment.

Anodic activity starts inside the scratch immediately after immersion, and the magnitude of the associated cationic flux is observed to increase with the elapse of time. Indeed, cations are observed to diffuse from all over the scratch. Conversely, SVET measurements show that the cathodic process mainly occurs below the coating, since the anionic fluxes are observed from the surrounding coated areas. The diffusing chemical species involved in the anodic half-cell reaction are Fe(II) ions which diffuse from inside the scratch into the bulk electrolyte. Dissolved molecular oxygen must diffuse from the electrolyte towards the surface of the coated metal, and subsequently permeate through the polymer matrix towards the metal-coating interface, to be combined with the electrons released by the metal in the anodes with the production of hydroxyl ions as products in the cathodic half-cell reaction. The slight change in colouring that may be observed in the sequence of micrographs taken in situ with the video microscope for the investigated sample with the elapse of time might be an indication that some precipitation of corrosion products (brownish iron oxyhydroxides) inside the artificial defect may already occur at the longest exposures under consideration (cf. Figure 5).

In summary, when the defective sample was imaged with the SVET during its immersion in $0.1 \mathrm{M} \mathrm{Na}_{2} \mathrm{SO}_{4}$ air-saturated aqueous solution, all the information from the maps is exclusively from ionic currents due to the diffusion of charged soluble species. Collection efficiency is thus hindered when product precipitation occurs [37], though this effect is regarded to be rather small in this case as supported by the optical images shown in Figure 5. On the other hand, SVET measurements support that the anodic process is distributed over the exposed metal inside the scratch, whereas the corresponding cathodic reactions are observed to occur below the coating in zones surrounding the defect.

\subsection{Imaging a scratch in epoxy-polyamine coated carbon steel during immersion in $10 \mathrm{mM}$} $\mathrm{NaCl}$. 
SVET images were also recorded during the exposure of a coated sample with a scratch to $10 \mathrm{mM} \mathrm{NaCl}$ solution. Selected maps are shown in Figure 6, and they allow the collection of surface information in the course of the corrosion process inside the scratch. Significant changes in the distribution of the cationic and anionic fluxes in the scanned area are observed with time. Within the first 10 min of exposure, a narrow anodic peak exhibiting rather high ionic currents due to the diffusion of the dissolving $\mathrm{Fe}^{2+}$ ions from the sample is clearly displayed. This is an indication that the anodic reaction is greatly localized compared to the total metal exposed inside the scratch, in an area found at the upper part of the scratch as depicted in the sequence of video micrographs given in Figure 7. The dissolution of iron may have started through the nucleation of a corrosion pit. On the other hand, the ionic fluxes related to the cathodic reaction are found to be distributed over a significantly greater surface, mainly above the coated surface at the right side of the scratch. The precipitation of corrosion products at this early exposure is also noticeable from the corresponding optical micrograph in figure 7, and it is observed to become more generalized over the scratch as time elapses.

SVET images taken at longer exposures show that the anodic activity further extends both over the metal exposed in the scratch and below the coating at the left of the defect (cf. Figures 6 B-D). This is an evidence of the onset of an anodic delamination process below the coating has occurred, and this initially takes place from the coated edge in the proximity of the site at which the corrosion of iron was initiated. Additionally, with the increase of the total area from which positive currents (i.e., anodic activity) are detected, the cathodic regions are observed to occur below the coating at bigger distances from the scratch.

\subsection{General observations.}

Regardless the nature of the test electrolyte employed, the cathodic process has been found to take place under the coating since the onset of corrosion, whereas the anodic activity was mainly observed inside the scratch, though its occurrence below the coating was also observed for longer exposures when the sample was exposed to $10 \mathrm{mM} \mathrm{NaCl}$ aqueous solution. For ionic currents to be detected over the coated areas, micropores must be present through the coating which may either exist from the manufacturing process, or be developed the corrosion process progresses. On the basis of a previous investigation on the corrosion protection characteristics of this metal-coating system conducted by electrochemical impedance spectroscopy [36], EIS spectra could be modelled considering the coating acted as a defective barrier film, which is consistent with a rather porous structure resulting from its manufacturing stage. A possible specific effect towards ionic permeation through the coating 
due to chloride may be temptatively proposed from the reported data as compared to the measurements in the sulphate-containing solution, and this will correlate well with observations conducted with scanning electrochemical microscopy for this system [38]. Yet, such proposed specific effect of chloride ions to promote coating delamination cannot be established unambiguously at this stage from the only consideration of our current data.

Another important effect in the system is related to the onset of product precipitation in the investigated system. Iron oxy-hydroxide species are formed when Fe(II) and hydroxyl ions liberated in the distributed anodic and cathodic regions are transported into the same electrolyte volume. The precipitation of these products may partially block the reacting metal surface, and may justify the progress of delamination below the coating with the elapse of time.

\section{Conclusions}

SVET imaging of defective polymer coated steel samples exposed to an aqueous electrolytic solution proves that the electrochemical behaviour of the system is quite different depending on the electrolyte employed.

The anodic activity, related to the electrodissolution of the underlying metal, occurs almost exclusively within the scratch in the sulphate-containing solution. Conversely, the cathodic activity is observed always below the coating around the defect, as followed by the diffusion of hydroxyl ions towards the electrolytic phase. The precipitation of iron oxyhydroxide may eventually take place from the electrolyte with the elapse of time, due to the local alkalinization of the aqueous phase in the proximity of the corroding sites. Furthermore, in $10 \mathrm{mM} \mathrm{Na}_{2} \mathrm{SO}_{4}$ solution, the anionic fluxes measured are smaller than those due to the cations, indicating that the anodic activity is more localized and the technique exhibits higher collection efficiency towards the metal ions in this case. This is a further confirmation that the cathodic sites are distributed under the coating. No significant changes in the magnitude of the ionic fluxes monitored by SVET with time is observed, which supports the observation that the precipitation of corrosion products only occurs in a small extent in this environment.

Greater anionic and cationic fluxes are measured by SVET for the same system when immersed in $10 \mathrm{mM} \mathrm{NaCl}$ aqueous solution, which is evidence that the corrosion process occurs faster in this environment. This effect may be temptatively attributed to a specific effect of chloride ions towards facilitating an increase transport of ionic species through the coating towards the metal-polymer interface. Delamination effects are also observed to occur in this case, when even anodic activity occurs below the coated areas, though still the main 
contributions towards metal electrodissolution are observed from the scratch. Increased precipitation of corrosion products is also observed.

To our knowledge, the detection of ionic fluxes related to the cathodic reaction from below the coated metal has been observed for the first time using SVET, which can be ascribed to the particular microporous characteristics of this coating already described on the basis of electrochemical impedance spectroscopy (EIS) data [36].

\section{Acknowledgements:}

This work was supported by the Ministerio de Ciencia y Tecnología (Madrid, Spain) under Project No. CTQ2009-14322. A grant awarded to JJS by the Gobierno de Canarias (Spain) to conduct a research stay at the University of La Laguna is gratefully acknowledged. Thanks are due to Sigma Coatings (Amsterdam, The Netherlands) for providing the coatings.

\section{References:}

1. Paints and varnishes - Electrochemical impedance spectroscopy (EIS) on highimpedance coated specimens. ISO 16773 norm. International Organization for Standardization, Geneva, 2007-2009.

2. F. Mansfeld, in Analytical Methods in Corrosion Science and Engineering, P. Marcus and F. Mansfeld (Eds.), CRC Press, Boca Raton (FL) 2006, p. 463.

3. G. Grundmeier, A. Simões, in Encyclopedia of Electrochemistry, Vol. 4 (Eds: A.J. Bard, M. Stratmann), Wiley-VCH, Weinheim 2003, p. 499.

4. M. Rohwerder and M. Stratmann, in Analytical Methods in Corrosion Science and Engineering (Eds: P. Marcus, F. Mansfeld), CRC Press, Boca Raton (FL) 2006, p.603.

5. M. Rohwerder, F. Turcu, Electrochim. Acta 2007, 53, 290.

6. S. Rossi, M. Fedel, F. Deflorian, M.C. Vadillo, Comptes Rendue Chim. 2008, 11, 984.

7. I. Sekine, Prog. Org. Coat. 1997, 31, 73

8. Local Probe Techniques for Corrosion Research (Eds: R. Oltra, V. Maurice, R. Akid, P. Marcus), Woodhead, Cambridge 2007.

9. R.S. Lillard, in Analytical Methods in Corrosion Science and Engineering, (Eds: P. Marcus, F. Mansfeld), CRC Press, Boca Raton (FL) 2006, p.571.

10. J.-B. Jorcin, E. Aragon, C. Merlatti, N. Pébère, Corros. Sci. 2006, 48, 1779.

11. C.F. Dong, A.Q. Fu, X.G. Li, Y.F. Cheng, Electrochim. Acta 2008, 54, 628.

12. A.C. Bastos, A.M. Simões, S. González, Y. González-García, R.M. Souto, Prog. Org. Coat. 2005, 53, 177. 
13. S.E. Pust, W. Maier, G. Wittstock, Z. Phys. Chem. 2008, 222, 1463.

14. L. Niu, Y. Yin, W. Guo, M. Lu, R. Qin, S. Chen, J. Mater. Sci. 2009, 44, 4511.

15. Y. González-García, J.J. Santana, J. González-Guzmán, J. Izquierdo, S. González, R.M. Souto, Prog. Org. Coat. 2010, in press.

16. R.M. Souto, Y. González-García, S. González, G.T. Burstein, Corros. Sci. 2004, 46, 2621.

17. R.M. Souto, Y. González-García, S. González, Corros. Sci. 2008, 50, 1637.

18. R.M. Souto, Y. González-García, S. González, Prog. Org. Coat. 2009, 65, 435.

19. R.M. Souto, Y. González-García, S. González, G.T. Burstein, Electroanalysis 2009, 21, 2569.

20. R.M. Souto, Y. González-García, J. Izquierdo, S. González, Corros. Sci. 2010, 52, 748.

21. R.M. Souto, Y. González-García, S. González, Corros. Sci. 2005, 47, 3312.

22. A.M. Simões, D. Battocchi, D.E. Tallman, G.P. Bierwagen, Corros. Sci. 2007, 49, 3838.

23. R.M. Souto, L. Fernández-Mérida, S. González, Electroanalysis 2009, 21, 2640.

24. D.A. Worsley, H.N. McMurray, A. Belghazi, Chem. Commun. 1997, 2369.

25. K. Ogle, V. Baudu, L. Garrigues, X. Philippe, J. Electrochem. Soc. 2000, 147, 3654.

26. J. He, V.J. Gelling, D.E. Tallman, G.P. Bierwagen, J. Electrochem. Soc. 2000, 147, 3661.

27. D.A. Worsley, D. Williams, J.S.G. Ling, Corros. Sci. 2001, 43, 2335.

28. D.A. Worsley, H.N. McMurray, J.H. Sullivan, I.P. Williams, J. Electrochem. Soc. 2002, 149, B154.

29. K. Ogle, S. Morel, D. Jacquet, J. Electrochem. Soc. 2006, 153, B1.

30. D.J. Penney, J.H. Sullivan, D.A. Worsley, Corros. Sci. 2007, 49, 1321.

31. G. Bierwagen, D. Battocchi, A. Simões, A. Stamness, D. Tallman, Prog. Org. Coat. 2007, 59, 172.

32. M.L. Zheludkevich, K.A. Yasaku, A.C. Bastos, O.V. Karavai, M.G.S. Ferreira, Electrochem. Commun. 2007, 9, 2622.

33. F. Thébault, B. Vuillemin, R. Oltra, K. Ogle, C. Allely, Electrochim. Acta 2008, 53, 5226.

34. A.M. Simões, J. Torres, R. Picciochi, J.C.S. Fernandes, Electrochim. Acta 2009, 54, 3857.

35. R.M. Souto, B. Normand, H. Takenouti, M. Keddam, Electrochim. Acta 2010, 55, 4551.

36. J. González-Guzmán, J.J. Santana, S. González, R.M. Souto, Prog. Org. Coat. 2010, 68, 240.

37. R.M. Souto, Y. González-García, A.C. Bastos, A.M. Simões, Corros. Sci. 2007, 49, 4568.

38. J.J. Santana, J. González-Guzmán, L. Fernández-Mérida, S. González, R.M. Souto, Electrochim. Acta 2010, 55, 4488. 


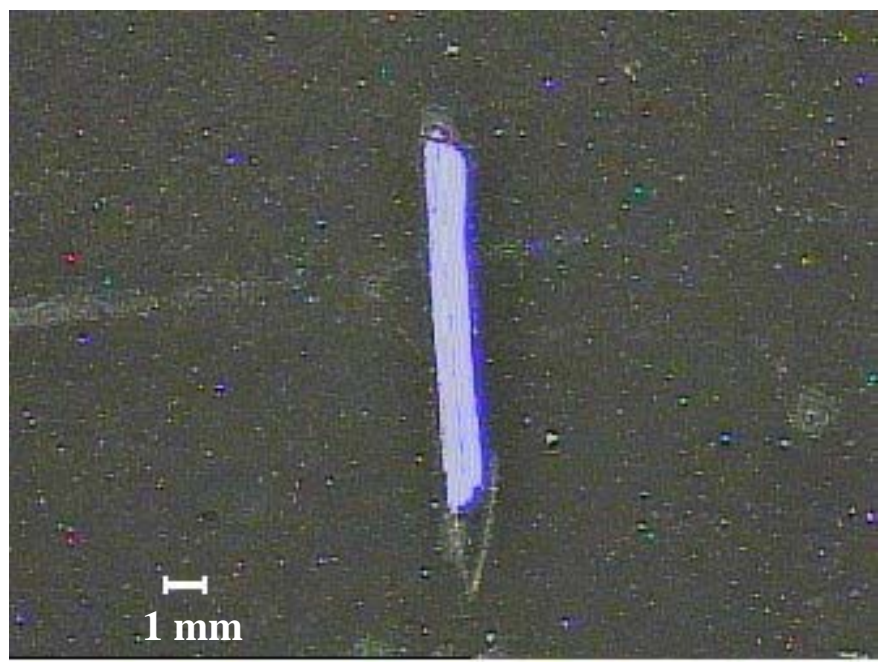

Figure 1. Optical image of scratch produced in the coated steel specimen with a scalpel.

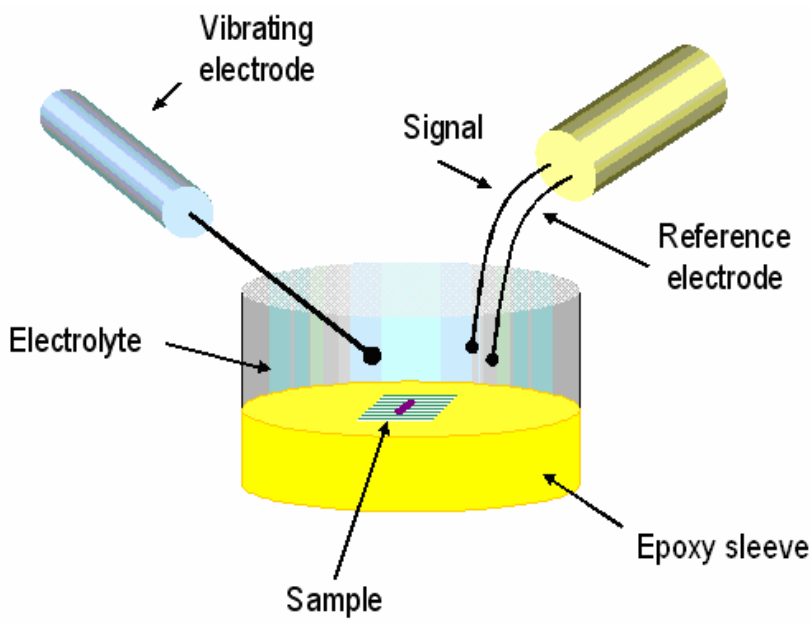

Figure 2. Sketch of the electrochemical cell employed in the SVET experiments.

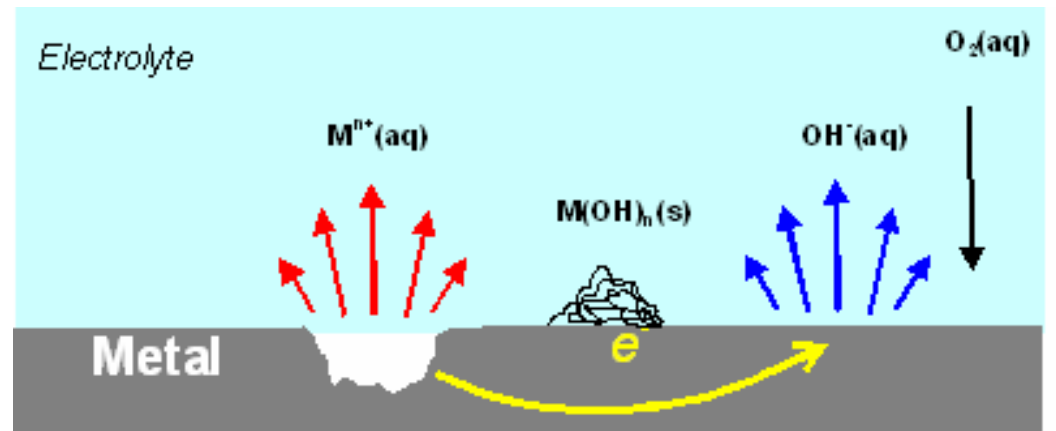

Figure 3. Schematic representation of a naturally corroding metal surface exposed to a neutral aqueous solution. The diffusion of the various ionic species involved in the corrosion reactions is indicated. 


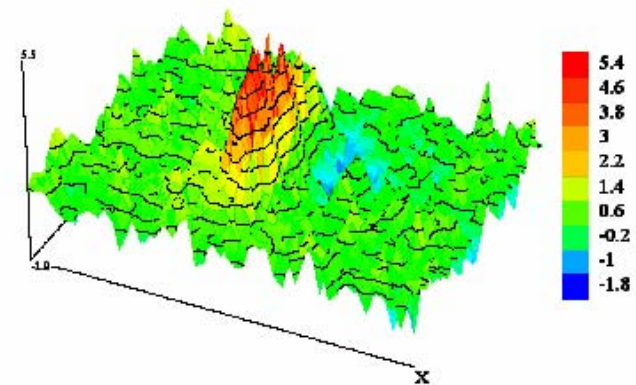

(A)

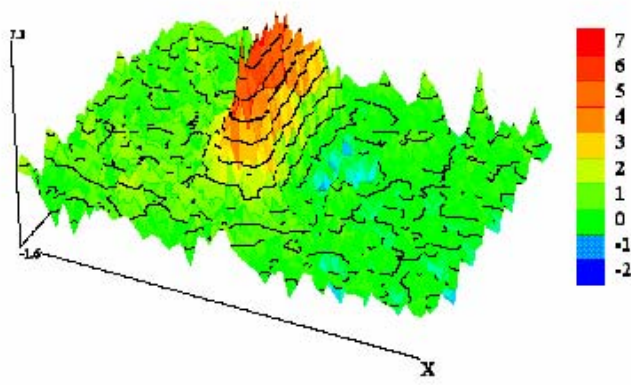

(C)

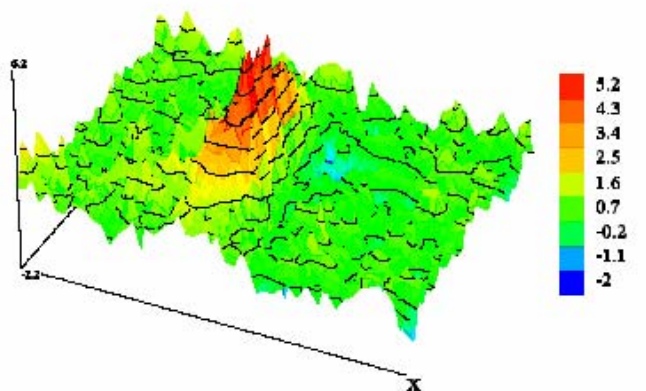

(B)

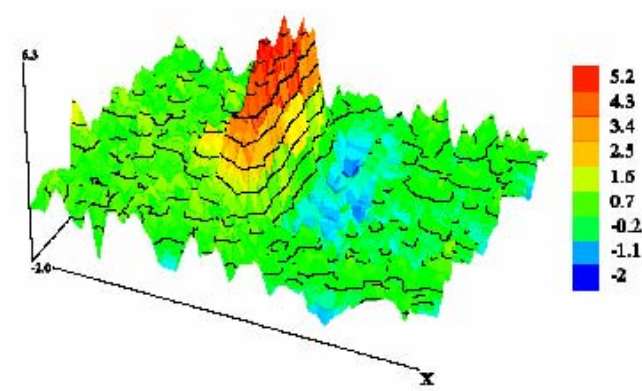

(D)

Figure 4. SVET images of a scratched polymer-coated carbon steel sample after immersion in $10 \mathrm{mM} \mathrm{Na} \mathrm{SO}_{4}$ air-saturated aqueous solution for: (A) 10, (B) 30, (C) 50, and (D) $70 \mathrm{~min}$. The time origin corresponds to the initiation of the scan. The figures represent an area of 900 $\mu \mathrm{m} \times 900 \mu \mathrm{m}$ in $X$ and $Y$ directions. Values of $Z$ axis: ionic current in $\mu \mathrm{A} \mathrm{cm}^{-1}$. Tip-substrate distance: $150 \mu \mathrm{m}$

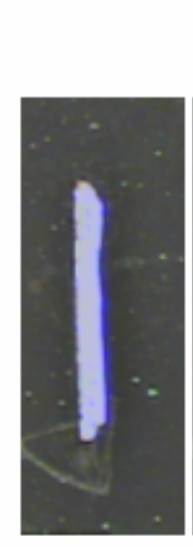

0 min
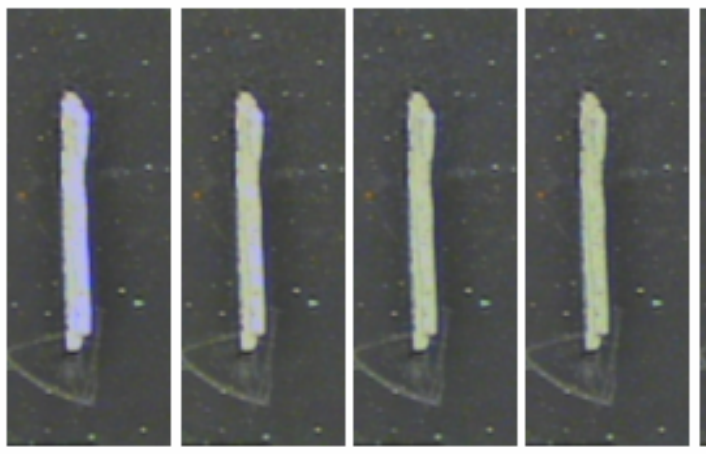

$\rightarrow$ time
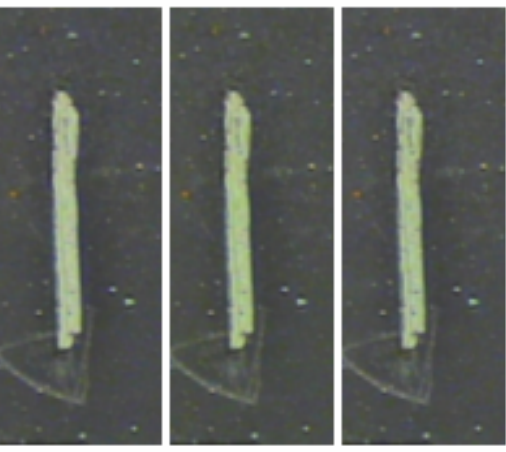

70 min

Figure 5. Optical micrograph images of the scratched polymer-coated carbon steel sample considered in Figure 4. They show the time evolution of the scratch during immersion in 10 $\mathrm{mM} \mathrm{Na}_{2} \mathrm{SO}_{4}$ air-saturated aqueous solution. 


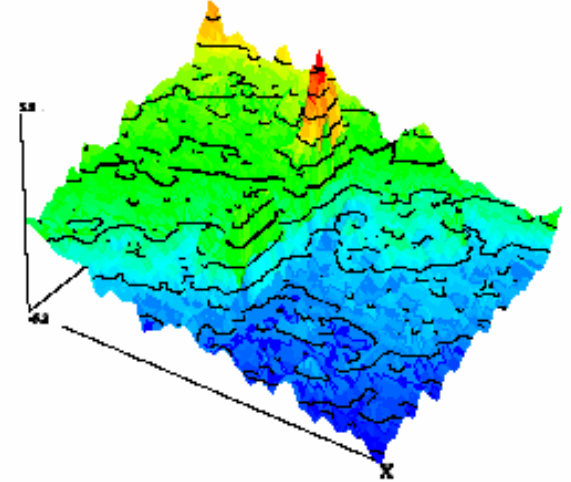

(A)

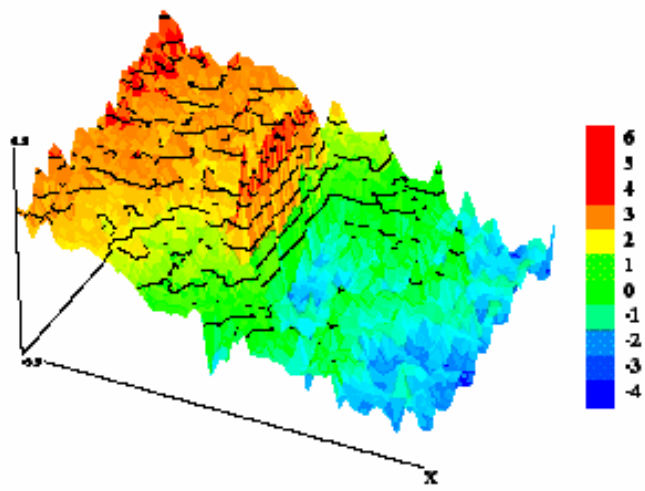

(C)

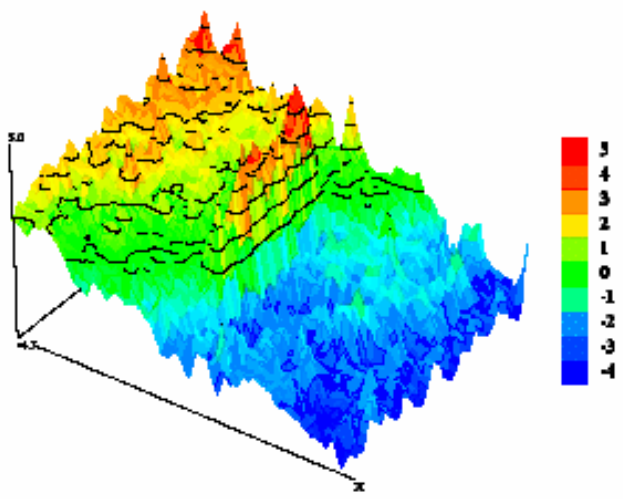

(B)

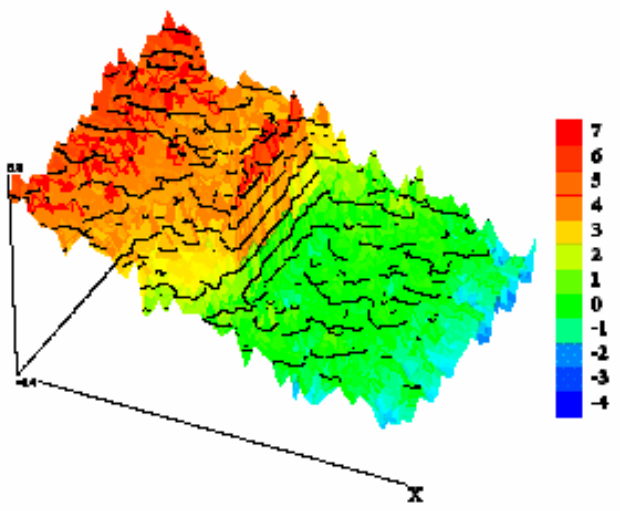

(D)

Figure 6. SVET images of a scratched polymer-coated carbon steel sample after immersion in $10 \mathrm{mM} \mathrm{NaCl}$ air-saturated aqueous solution for: (A) 10, (B) 30, (C) 50, and (D) $70 \mathrm{~min}$. The time origin corresponds to the initiation of the scan. The figures represent an area of $900 \mu \mathrm{m} \mathrm{x}$ $900 \mu \mathrm{m}$ in $X$ and $Y$ directions. Values of $Z$ axis: ionic current in $\mu \mathrm{A} \mathrm{cm}{ }^{-1}$. Tip-substrate distance: $150 \mu \mathrm{m}$.

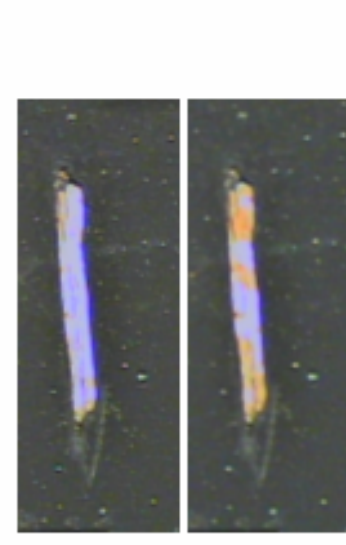

0 min
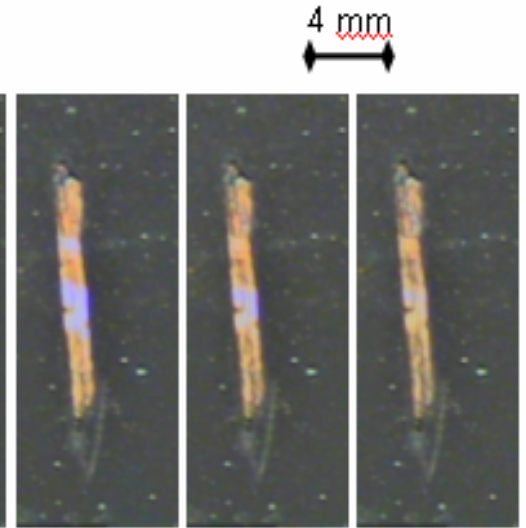

$\rightarrow$ time
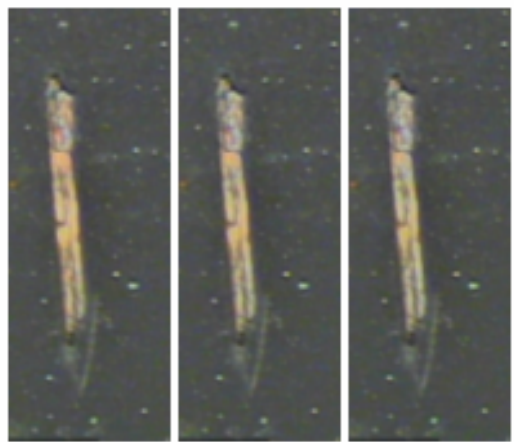

$70 \mathrm{~min}$

Figure 7. Optical micrograph images of the scratched polymer-coated carbon steel sample considered in Figure 6. They show the time evolution of the scratch during immersion in 10 $\mathrm{mM} \mathrm{NaCl}$ air-saturated aqueous solution. 